Revista Bioética

\title{
ATUALIZAÇÃO
}

\section{Diretivas antecipadas de vontade: proposta de instrumento único}

Sergio Domingos Pittelli ${ }^{1}$, Reinaldo Ayer de Oliveira ${ }^{1}$, Janice Caron Nazareth ${ }^{2}$

1. Universidade de São Paulo, São Paulo/SP, Brasil. 2. Hospital Alemão Oswaldo Cruz, São Paulo/SP, Brasil.

\section{Resumo}

O objetivo deste estudo é refletir sobre as características e finalidades do documento de diretivas antecipadas de vontade do paciente. Conclui-se que tal documento deve ter formato único, que reflita a generalidade dos termos da Resolução 1.805/2006 do Conselho Federal de Medicina, e que sua principal finalidade é fortalecer a sensação de segurança jurídica do profissional médico. Por fim, destaca-se que, ainda que se considerem as determinações escritas, prevalecerá o entendimento entre paciente e equipe.

Palavras-chave: Bioética. Diretivas antecipadas. Doente terminal.

\section{Resumen}

Directivas anticipadas de voluntad: propuesta de instrumento único

El objetivo de este estudio es hacer consideraciones sobre las características y propósitos del documento relativo a las directivas anticipadas de voluntad del paciente. Se concluye que debe tener un formato único, que refleje los términos generales de la Resolución 1.805/2006 del Consejo Federal de Medicina, y que su principal propósito es fortalecer la percepción de seguridad jurídica del profesional médico. Finalmente, se enfatiza que, incluso si se consideran las determinaciones escritas, prevalecerá el entendimiento entre el paciente y el equipo.

Palabras clave: Bioética. Directivas anticipadas. Enfermo terminal.

\section{Abstract}

\section{Advance directives: a standard instrument proposal}

This study aimed to reflect on the characteristics and objectives of the patient's advance directives. This document should have a standard format, including the general terms of Resolution 1.805/2006 of the Federal Council of Medicine, and strengthen the sense of legal certainty of health professionals. Even with written determinations, the understanding between patient and staff shall prevail. Keywords: Bioethics. Advance directives. Terminally ill. 
Nos últimos anos, houve notáveis mudanças no modo como o processo da morte e os momentos finais da vida são entendidos. Dentre elas, destacam-se a contestação do paradigma "manter a vida a qualquer custo", que definia o fim da vida exclusivamente pela parada cardíaca irreversível seguida da morte das células do organismo, e a atenção que passou a ser dada à vontade do paciente na condução do tratamento. Como efeitos dessa segunda mudança, podem ser citados o direito à informação esclarecida e o dever do médico de dialogar com o paciente para adotar medidas terapêuticas.

As mudanças se refletiram na legislação de países que regulamentaram a relação médico-paciente (particularmente no que diz respeito a decisões sobre terapêuticas) e elementos inerentes a ela, como o direito de recusa ao tratamento e modos de manifestar essa vontade. Passou-se a admitir que, em casos de doença grave e incurável, o paciente, em conjunto com a equipe médica, decida pela suspensão de terapêuticas inúteis, mantendo medidas de conforto e alívio da dor e do sofrimento. Tornaram-se relevantes, então, as noções de terminalidade e cuidados paliativos.

As leis variam em abrangência. Este artigo não se propõe a realizar estudo de direito comparado, mas cabe apontar algumas características comuns a diversos países. Todo diploma desse tipo, por exemplo, limita o poder de pacientes e médicos aos ditames da lei; nada que a lei do país proíba pode ser acordado entre médico e paciente ou disposto em instrumento de manifestação da vontade. Todas elas também facultam ao paciente desistir das determinações prévias a qualquer momento, sem maiores formalidades, e tratam da figura do procurador para fins específicos, quando o paciente estiver impossibilitado de exprimir sua vontade, seja por deficiência cognitiva, seja por estar em coma.

Quanto à forma como a vontade deve ser manifestada, há variações importantes. Neste ponto, pode-se dizer que há dois paradigmas: a lei americana (Patient Self Determination Act of 1990) ${ }^{1}$ e a australiana (Consent to Medical Treatment and Palliative Care Act, de 1995, modificada em 2004) ${ }^{2}$. A primeira é curta e "informal", no sentido de que não estabelece ritos nem obriga a que a manifestação seja registrada por escrito. As diretivas podem ser redigidas, mas o documento não é obrigatório: são descritas apenas algumas condutas a que se obrigam médicos ou instituições de atendimento, bem como os direitos do paciente. A lei australiana, por sua vez, é bem mais detalhada e obriga a que a manifestação seja escrita, estabelecendo um formulário e criando um cadastro nacional de diretivas a ser consultado no momento do atendimento. Em termos gerais, esse padrão é seguido pela Lei $25 / 2012^{3}$, portuguesa, e pela Lei $41 / 2002^{4}$, espanhola, também com cadastro nacional de diretivas.

No Brasil não existe lei federal que regulamente a matéria. Há leis estaduais, como a Lei 10.241/1999 5 do estado de São Paulo (a chamada "Lei Mário Covas") e a Lei 3.613/2001 ${ }^{6}$ do estado do Rio de Janeiro. As duas, bastante semelhantes, não dispõem sobre terminalidade e diretivas antecipadas como as citadas leis estrangeiras, tocando apenas de passagem em direitos como o direito à informação, o direito de recusa ao tratamento e o direito de escolha do local da morte. As únicas normas federais relativas à matéria são as resoluções do Conselho Federal de Medicina (CFM) 1.805/2006 e 1.995/2012 ${ }^{8}$.

A Resolução CFM 1.805/2006 regulamenta a conduta do médico em casos de pacientes com doença grave e incurável em fase terminal. Sem contar o último, que trata do aspecto formal do início da vigência, a norma contém apenas dois artigos. O caput do primeiro é tipicamente permissivo: autoriza o médico a limitar ou suspender procedimentos e tratamentos que prolonguem a vida do doente em fase terminal ${ }^{7}$, sempre respeitando, em qualquer circunstância, a vontade do paciente ou de seu representante legal. Este artigo tem três parágrafos de teor imperativo: o médico é obrigado a esclarecer o paciente ou representante legal sobre as modalidades terapêuticas adequadas a cada situação (§ 1ㅇ); a decisão referida no caput deve ser fundamentada e registrada no prontuário ( $\$ 2$ ); e é assegurado ao doente ou a seu representante legal o direito de solicitar uma segunda opinião $(\S 30)^{7}$. O segundo artigo dessa resolução determina que o paciente continuará a receber todos os cuidados necessários para aliviar (...) sofrimento (...) físico, psíquico, social e espiritual?

Além da concisão, por si só característica notável, levando-se em conta seu objeto, a norma tem três outras características que condizem com essa brevidade e a permitem. A primeira delas é a generalidade: conceitos como "terminalidade" e "paciente terminal", principalmente, e mesmo "enfermidade grave e incurável", não são precisamente definidos, mas tratados como evidentes por si mesmos. Em linguagem legal, pode-se dizer que são tratados como "standard jurídico". Gimenes expressa bem essa ideia de imprecisão: o momento a partir do qual a terapêutica não produz mais efeitos e a sua manutenção seria apenas uma forma de prolongar o sofrimento do paciente é perfeitamente possivel de se determinar na maioria dos casos, em especial nos pacientes crônicos em fase terminal ${ }^{9}$. 
A segunda característica é o caráter casuístico e pessoal que deriva da ausência de definição dos conceitos, pois o texto acaba por atribuir à opinião do médico o diagnóstico do paciente como portador ou não de enfermidade em fase terminal. Por fim, a terceira característica é a presença do "representante legal" ao lado de "doente" ou "pessoa" em todos os dispositivos cujo objeto implica decisão (art. 1으, caput, $\S 1$ e $\S 3$ ㅇ) ${ }^{7}$.

A Resolução CFM 1.995/2012 ${ }^{8}$ regulamenta as chamadas "diretivas antecipadas de vontade" e, como a anterior, tem apenas dois artigos referentes ao seu objeto. Sua principal característica também é a generalidade. As diretivas são definidas em seu primeiro artigo como conjunto de desejos, prévia e expressamente manifestados pelo paciente ${ }^{8}$, sobre como quer ser tratado caso não tenha condições de manifestar sua vontade. Não se descrevem quais elementos podem ou não ser incluídos no rol dos "desejos"; a limitação apresentada no § 20 do artigo $2^{\circ}{ }^{8}$ é genérica e dada pela negativa, nos moldes das leis de outros países já comentadas neste texto: as diretivas não podem incluir determinações que estejam em desacordo com o Código de Ética Médica (o que equivale a dizer, neste caso específico, que não podem estar em desacordo com as leis).

Uma segunda característica da Resolução CFM 1.995 $/ 2012^{8}$ é a presença, já notada na norma anterior, da figura do "representante", citado expressamente e nestes termos no $\S 1$ 은 do artigo 2 . . Uma terceira e última característica relevante é negativa: não se exige que as determinações sejam feitas por escrito, mas apenas que o médico as anote no prontuário, seguindo o padrão do CFM para esse tipo de documento.

Terminada a apresentação das duas normas, antes de continuar a exposição, duas observações se fazem oportunas. A primeira é que, até o momento, não há dados convincentes na literatura médica que comprovem que determinações escritas são mais eficazes do que manifestações orais no sentido de serem mais bem compreendidas e de fato cumpridas. A dificuldade maior é fazer o documento chegar ao conhecimento da equipe médica, sobretudo em setores de emergência, onde é comum receber pacientes com rebaixamento do estado de consciência ou mesmo inconscientes. Nesses casos, quando não há documento com diretivas, o médico tende a proceder de acordo com práticas características da cultura médica vigente.

A segunda observação é a de que os termos genéricos das duas normas atendem, por um lado, à relação médico-paciente e à natureza casuística e concreta dos fatos relativos ao estado de saúde das pessoas e, por outro, à possibilidade quase infinita de situações clínicas que levam à morte (ou que possam ser objeto de escrutínio da vontade do paciente, mesmo que não se trate de caso terminal), as quais em geral só se definem quando muito próximas do desenlace. Tais circunstâncias não permitiriam detalhamentos com apreciável antecipação temporal - do contrário se configuraria espécie de exercício de adivinhação.

Posto isso, entende-se que a elaboração de documento escrito, a exemplo do que ocorre com todas as formas de manifestação da vontade, presta-se mais a servir de prova e a garantir segurança jurídica a quem aplica as diretivas do que a propriamente estabelecer com precisão a vontade do paciente. Tal vontade, se for o caso, será manifestada pelo próprio enfermo ou por seu representante no momento apropriado, quando se definirem as condições clínicas de terminalidade.

Admitido tal documento, suas características deveriam refletir a generalidade das duas resoluções que normatizam a matéria. Assim, apesar da complexidade e variedade das situações de fim de vida, o documento seria relativamente simples e com padrão único, baseado fundamentalmente na Resolução CFM 1.805/2006 ${ }^{7}$, inclusive com expressões nela constantes. O Anexo deste artigo pode servir de modelo para esse tipo de instrumento, a ser apresentado no formato típico de declaração preferencialmente pública - de vontade, após introdução-padrão para a espécie.

\section{Discussão}

O texto apresentado (Anexo) é genérico, abrangente e afasta o que normalmente se entende por "tratamento fútil", determinando a suspensão apenas de terapêuticas que se enquadrem neste conceito. Qualquer situação não prevista será resolvida pelo próprio declarante ou, em caso de impossibilidade de manifestação, por procurador indicado, no momento em que se apresentar a questão (ressalta-se, portanto, a importância do procurador). Não há espaço para registrar os procedimentos a que o declarante deseja ou não ser submetido para prolongar sua vida caso esteja internado em unidade de terapia intensiva ${ }^{10}$, uma vez que é desnecessário identificá-los de modo específico e detalhado e é impossível fazê-lo com antecedência.

A mesma observação vale para recomendações a respeito de sequelas ${ }^{10}$, primeiro porque não se trata 
de quadro terminal e, a depender do grau de impedimento cognitivo, as decisões podem ser tomadas pelo próprio paciente, por seu procurador, ou mesmo por membro da família que assuma informalmente a função de cuidador - o que é frequente nessas situações. De todo modo, é impossível prever que tipo de sequela sobrevirá caso haja algum evento danoso à saúde (a própria natureza do evento é imprevisível), e a decisão só poderá ser tomada em face do quadro instalado, não se prestando, portanto, a integrar textos preparados previamente.

Para Dadalto, devem constar no documento aspectos relativos ao tratamento médico, como a Supressão do Esforço Terapêutico (SET), o desejo do paciente quanto à não utilização de máquinas e previsões relativas a intervenções médicas que não deseja receber, entre outras ${ }^{11}$. A autora incide, no entanto, no mesmo equívoco de tentar definir procedimentos imprevisíveis. Sem a reconhecer expressamente, Dadalto ${ }^{12}$ manifesta a dificuldade em estabelecer diretrizes com antecedência ao citar como limite à declaração prévia de vontade o aparecimento de novas terapias que possibilitem tratar a doença do paciente, descaracterizando, assim, a obstinação terapêutica.

Ainda segundo Dadalto ${ }^{12}$, a doutrina entende por "diretivas antecipadas" o gênero de que são exemplo a declaração prévia de vontade do paciente terminal e o mandato duradouro - que pode e deve integrar a primeira e aplica-se inclusive a situações de incapacidade transitória (não terminal, portanto). De todo modo, valem para este último as mesmas limitações relativas à impossibilidade de antecipar detalhes, o que reforça a necessidade e importância da figura do mandatário.

\section{Considerações finais}

Conclui-se que não é possível estabelecer em detalhes e com anterioridade, sob forma escrita, quais medidas deverão ou não ser tomadas caso o paciente não esteja em condições de tomar decisões - até porque tais medidas, a princípio, resumem-se à suspensão de todo procedimento que se enquadre no conceito-padrão de "tratamento fútil". Assim, propõe-se o termo genérico e abrangente transcrito no Anexo deste artigo. Sua finalidade é fortalecer a sensação de segurança do profissional médico, e não substituir o diálogo entre a equipe e o paciente e sua família ou procurador. As determinações contidas no documento podem ser revogadas por mera manifestação verbal, a qualquer momento.

\section{Referências}

1. United States of America. H.R.4449. Patient Self Determination Act of 1990. Congress [Internet]. Washington, 4 mar 1990 [acesso 13 nov 2019]. Disponível: https://bit.ly/3jLD99j

2. South Australia. Consent to Medical Treatment and Palliative Care Act 1995. South Australian Legislation [Internet]. 1995 [acesso 13 nov 2019]. Disponível: https://bit.ly/36AOPcl

3. Portugal. Lei $n=25$, de 16 de julho de 2012. Regula as diretivas antecipadas de vontade, designadamente sob a forma de testamento vital, e a nomeação de procurador de cuidados de saúde e cria o Registo Nacional do Testamento Vital (Rentev). Diário da República [Internet]. Lisboa, no 136/2012, 16 jul 2012 [acesso 13 nov 2019]. Série 1. Disponível: https://bit.ly/36ACu6G

4. España. Ley $n$ o 41 , de 14 de noviembre de 2002. Regula la autonomía del paciente y los derechos y obligaciones en materia de información y documentación clínica. Boletín Oficial del Estado [Internet]. Madrid, no 274, 15 nov 2012 [acesso 13 nov 2019]. Disponível: https://bit.ly/34quTF5

5. São Paulo (estado). Lei no 10.241, de 17 de março de 1999. Dispõe sobre os direitos dos usuários dos serviços e das ações de saúde no estado. Diário Oficial do Estado de São Paulo [Internet]. São Paulo, v. 109, no 51, p. 1, 18 mar 1999 [acesso 13 nov 2019]. Seção 1. Disponível: https://bit.ly/3d8BPuA

6. Rio de Janeiro (estado). Lei no 3.613, de 18 de julho de 2001. Dispõe sobre os direitos dos usuários dos serviços e das ações de saúde no estado do Rio de Janeiro e dá outras providências. Diário Oficial do Estado do Rio de Janeiro [Internet]. Rio de Janeiro, 19 jul 2001 [acesso 13 nov 2019]. Disponível: https://bit.ly/3lizdgC

7. Conselho Federal de Medicina. Resolução CFM no 1.805, de 9 de novembro de 2006. Na fase terminal de enfermidades graves e incuráveis é permitido ao médico limitar ou suspender procedimentos e tratamentos que prolonguem a vida do doente, garantindo-lhe os cuidados necessários para aliviar os sintomas que levam ao sofrimento, na perspectiva de uma assistência integral, respeitada a vontade do paciente ou de seu representante legal. Diário Oficial da União [Internet]. Brasília, no 227, p. 169, 28 nov 2006 [acesso 13 nov 2019]. Seção 1. Disponível: https://bit.ly/3d2XjsH

8. Conselho Federal de Medicina. Resolução CFM no 1.995, de 9 de agosto de 2012. Dispõe sobre as diretivas antecipadas de vontade dos pacientes. Diário Oficial da União [Internet]. Brasília, p. 269-70, 31 ago 2012 [acesso 13 nov 2019]. Seção 1. Disponível: https://bit.ly/36zCWCg

9. Gimenes AC. Ortotanásia. In: Scalquette ACS, Camillo CEN, coordenadores. Direito e medicina: novas fronteiras da ciência jurídica. São Paulo: Atlas; 2015. p. 111-34. p. 117. 
10. Lippmann E. Testamento vital: o direito à dignidade. São Paulo: Matrix; 2013.

11. Dadalto L. Testamento vital. Rio de Janeiro: Lumen Juris; 2010. p. 73.

12. Dadalto L. Op. cit.

Participação dos autores

Sergio Domingos Pittelli concebeu o artigo, redigiu o texto e realizou a revisão bibliográfica. Todos os autores discutiram e corrigiram o texto.

\section{Correspondência}

Sergio Domingos Pittelli - Rua Alberto Faria, 91 CEP 05459-000. São Paulo/SP, Brasil.

Sergio Domingos Pittelli - Doutor - sergio@pittelli.adv.br

(D) 0000-0002-9603-2335

Reinaldo Ayer de Oliveira - Doutor - rayer@usp.br

(D) 0000-0001-6861-9481

Janice Caron Nazareth - Especialista - gericlin@terra.com.br

(D) 0000-0003-0808-4600

Recebido: $\quad 6.7 .2019$

Revisado: 25.8 .2020

Aprovado: 26.8 .2020 


\section{Anexo}

\section{Proposta de documento de diretivas antecipadas de vontade}

Saibam quantos esta pública escritura de declaração de vontade virem que, aos __ dias do mês de do ano nesta cidade de em cartório a meu cargo, perante tabelião e cinco testemunhas idôneas e capazes, adiante devidamente qualificadas e afinal assinadas, especialmente convocadas a este ato, compareceu, como outorgante declarante, o(a) sr(a). , de nacionalidade estado civil , de profissão domiciliado(a) na rua ___ pessoa nossa conhecida e reconhecida da própria, de mim, tabelião, e das mencionadas cinco testemunhas, as quais comigo se certificaram que ele(a), outorgante, se encontra em perfeito juízo, claro entendimento e livre de qualquer coação, induzimento ou sugestão, do que tudo eu, tabelião, dou fé. E logo, sempre em presença das aludidas cinco testemunhas, pelo(a) outorgante me foi dito que, por via da presente e nos meIhores termos de direito, vem fazer a presente declaração e afirmar sua vontade, em exercício pleno da autonomia que Ihe confere a Constituição da República Federativa do Brasil, na conformidade de suas declarações, prestadas na língua nacional, as quais, eu, oficial público em exercício, escrevi neste livro de notas, e são as seguintes: 1ạ) que o declarante é natural de onde nasceu no dia sendo filho de ; 2a) que vive maritalmente com $3^{\text {a })}$ que tem como filho(a)(s) ___ nascido(a)(s) no dia , casado(a)(s); 4aㅡ) que tendo o direito de manifestar a sua vontade sobre seu tratamento médico, podendo consentir ou recusar formas de tratamento e métodos diagnósticos, conforme lhe faculta a Constituição Brasileira (art. 1ㅇ, III, e art. 5ㅇ, II), o Código Civil brasileiro (Lei 10.406/2002, art. 15), a Resolução CFM 1.805/2006, a Resolução CFM 1.995/2012 e o Código de Ética Médica (Resolução CFM 2.217/2018, art. 41, parágrafo único), na hipótese em que se encontre em fase terminal de enfermidade grave e incurável, assim declarado por seu médico assistente, estando em casa ou em hospital, mesmo sem condições de manifestar sua vontade, declara que não consente no prolongamento artificial de sua vida nem na instauração de quaisquer medidas que possam ser enquadradas no que no meio profissional da saúde e na literatura especializada se conceitua como "obstinação terapêutica" (também referida como "excesso terapêutico", "tratamento fútil" ou "tratamento inútil", entre outras denominações), caracterizada pelo fato de visar exclusivamente o prolongamento da vida da pessoa, sem qualquer possibilidade de cura ou retorno a modo de vida saudável, e que inclui, entre outras e a título apenas exemplificativo, manobras de ressuscitação cardiorrespiratória, manobras destinadas a manter artificialmente a ventilação pulmonar por qualquer meio (intubação, traqueostomia ou pulmão mecânico), manobras invasivas no sentido de manter o débito cardíaco e a pressão arterial, incluindo reposição de volume e drogas vasoativas, bem como internação em unidade de terapia intensiva, restando permitido aos profissionais de saúde apenas o provimento de cuidados necessários e suficientes para o alívio da dor e do sofrimento, tanto físico quanto espiritual (assim chamados "cuidados paliativos"); a presente declaração estende-se a tratamentos de natureza não ressuscitadora, tais como, exemplificativamente, quimioterapia, radioterapia e procedimentos cirúrgicos e/ou invasivos de pequeno, médio ou grande porte, cuja realização ou não, estando o(a) declarante incapacitado(a) de decidir, será apreciada e decidida pelos procuradores abaixo nomeados; 5a) que admite, em havendo indicação da equipe médica, devidamente esclarecida, a extubação paliativa, a sedação paliativa e a supressão de medidas de alimentação não naturais, podendo os procuradores abaixo nomeados assim autorizar, se for o caso; 6ㅁ) que os efeitos da presente declaração antecipada de vontade se operem plenamente quando o(a) declarante tiver perdido de forma irreversível a capacidade de manifestar sua vontade, devendo a determinação expressa nesta declaração ser respeitada e cumprida por sua família, amigos e profissionais que lhe assistirem, isentando-se tais pessoas de qualquer responsabilidade no que respeita à pessoa do(a) declarante e seus sucessores; 7aa que entre as testemunhas presentes nomeia como seus representantes e procuradores, para que façam cumprir a sua vontade e decidam questões não definidas neste texto, quando não mais puder manifestar-se, as seguintes: a) _____ (qualificação) e b) ____ (qualificação), um em falta ou impedimento do outro. E, assim, disse-me ele(a), declarante, tinha por feitas e concluídas as suas disposições em declaração antecipada de vontade, pelo que me pediu e lhe lavrei esta escritura, a mim hoje distribuída, a qual feita, eu, tabelião, li ao declarante, em voz alta, clara e pausada, em presença das cinco aludidas testemunhas e, por conforme, inteiramente, com seu desejo e declarações, prestadas na língua portuguesa, aceitou, outorgou e assina, com ditas testemunhas, que são: , todas maiores, capazes, minhas conhecidas, aqui domiciliadas, presentes em todo o ato continuado desta declaração, no qual, porto por fé, foram cumpridas e observadas todas as formalidades e disposições legais. Eu, tabelião, o escrevi, subscrevo e assino, em público e raso. Nada mais, dou fé. 